\title{
A computed tomography study on the correlation between the morphometry of the suprascapular notch and anthropometric measurements of the scapula
}

\author{
M. Polguj ${ }^{1}$, A. Majos², M. Waszczykowski ${ }^{3}$, J. Fabiśs ${ }^{3}$, L. Stefańczyk ${ }^{4}$, M. Podgórski ${ }^{5}$, M. Topol ${ }^{5}$ \\ ${ }^{1}$ Department of Angiology, Interfaculty Chair of Anatomy and Histology, Medical University of Lodz, Poland \\ ${ }^{2}$ Department of Radiological and Isotopic Diagnosis and Therapy, Medical University of Lodz, Poland \\ ${ }^{3}$ Clinic of Arthroscopy, Minimally Invasive Surgery and Sports Traumatology, Medical University of Lodz, Poland \\ ${ }^{4}$ Department of Radiology, Medical University of Lodz, Poland \\ ${ }^{5}$ Department of Normal and Clinical Anatomy, Interfaculty Chair of Anatomy and Histology, \\ Medical University of Lodz, Poland
}

[Received: 14 April 2015; Accepted: 8 September 2015]

Background: The suprascapular notch is a clinically important site because it is the main site of injury and compression of the suprascapular nerve. Its shape and size are the most important factors in the aetiopathology of suprascapular nerve neuropathy. This article reports the first computed topography (CT) study on the correlation between the diameters of the suprascapular notch and anthropometric measurements of the human scapula.

Materials and methods: A total of 130 scans of shoulders by a helical 32-row multidetector CT scanner were retrospectively analysed. The following scapular measurements were performed: morphological length, morphological width, projection length of the scapular spine, maximal width of the scapular spine, length of the acromion, maximal length of the coracoid process, length of the superior border of the scapula, morphological height of the supraspinous fossa, length of the lateral border of the scapula, and morphological height of infraspinous fossa. The following suprascapular notch dimensions were measured: maximal depth, superior transverse diameter, middle transverse diameter.

Results: The maximum depth of the suprascapular notch correlates with the morphological length of the scapula, the length of the lateral border of the scapula and the morphological width of the scapula. The superior transverse diameter of the suprascapular notch correlates with the length of the superior border of the scapula and negatively with the length of the lateral border of the scapula. In addition it has been shown that the length of the superior border of the scapula correlates more closely with the superior transverse diameter of the suprascapular notch than the middle transverse diameter of the suprascapular notch.

Conclusions: It could be supposed that humans with longer scapulae have deeper notches. It may be also concluded that scapulae with a wider superior border have a shallower suprascapular notch. (Folia Morphol 2016; 75, 1: 87-92)

Key words: suprascapular notch, variation, scapula, correlation

Address for correspondence: M. Polguj, MD, PhD, Department of Angiology, Interfaculty Chair of Anatomy and Histology, Medical University of Lodz, ul. Narutowicza 60, 90-136 Łódź, Poland, tel: +42 63049 49; e-mail: michal.polguj@umed.lodz.pl 


\section{INTRODUCTION}

The suprascapular notch (SSN) is one of the most clinically important parts of the scapula. It is the main site of both injury and compression of the suprascapular nerve (SN) $[16,20]$. The anatomy of the structures surrounding the SSN is complex and of great significance because morphological variations may predispose the patient to compression of the SN $[5,13,18,20]$. Also, as the SSN is variform, its shape and size are the most important factors in the aetiopathology of SN entrapment [1, 11, 17]. Therefore, knowledge of the morphology of the suprascapular region, especially the SSN, is particularly important in various techniques associated with arthroscopic SN decompression [3, 7, 8] or ultrasound-guided blockage of the SN [15].

Gerard-Bialko [6] described a method of measuring the morphological length and morphological width of the scapula during the intravital anthropometric study in patients in different age groups. As it is now possible to identify certain dimensions of intravital shoulders, it may be valuable to confirm whether these parameters correlate with the dimensions of the SSN.

According to a current bibliography search, only 3 descriptions exist of the correlation between the diameters of the SSN and anthropometric measurements of the human scapula [1, 12, 19]. These are based on the classical anthropometric measurements of the dry scapula. However, no one investigated the correlation based on a second complementary, but independent method like computed tomography (CT) investigation.

This article reports the first radiological study so far on the correlation between the diameters of the SSN and anthropometric measurements of the human scapula. Hence, this study contrasts with earlier observations, which have been based only on classical anthropometric methods.

\section{MATERIALS AND METHODS}

A total of 130 CT scans of shoulders (65 patients) were retrospectively analysed between April 2009 and April 2011. Helical CT was performed with a 32-row multidetector CT scanner (Toshiba Aquilion 32; Toshiba Medical System, Japan). The raw data of shoulders' were analysed with post processing tools what provided: multiplanar reconstruction (MPR) and maximum intensity projection (MIP) images along the sagittal and coronal planes, coronal curved MIP images, 3-dimensional volume rendering images. The criteria of exclusion were scapula injury and previous scapular surgery. Also patients with metastases to bones or active neoplasmatic disease were excluded from the study. In the study, all procedures took place in accordance with the ethical standards of the responsible committee on human experimentation (institutional and national) and with the Helsinki Declaration of 1975, as revised in 2008. The research project was approved also by the Bioethics Commission of the Medical University of Lodz (protocol No. RNN/12/10/KE).

All measurements were performed using Vitrea 2 system software (Vital Images, Plymouth, MN, USA). Each of the CT scans of the shoulder area was carefully observed by 2 investigators.

The following scapular measurements were performed on the CT scans: morphological length, morphological width, projection length of the scapular spine, maximal width of the scapular spine, length of the acromion, maximal length of the coracoid process, length of the superior border of the scapula, morphological height of the supraspinous fossa, length of the lateral border of the scapula, and morphological height of infraspinous fossa (Fig. 1) [9].

The SSN dimensions were defined as follows (Fig. 2) $[12,14]$ :

1. The maximal depth (MD) - the maximum value of the longitudinal measurements taken in the vertical plane from an imaginary line between the superior corners of the notch to the deepest point of the SSN.

2. The superior transverse diameter (STD) - the maximum value of the horizontal measurements taken in the horizontal plane between the corners of the SSN on the superior border of the scapula.

3. The middle transverse diameter (MTD) - the value of the horizontal measurements taken in the horizontal plane between the opposite walls of the SSN at a midpoint of the maximal depth and perpendicular to it.

\section{Statistical analysis}

The statistical analysis was performed using Statistica 10 software (StatSoft Polska, Cracow, Poland). The normality of the distribution of continuous variables was investigated using the Shapiro-Wilk test. The correlation between the SSN measurements and basic anthropometric measurements of the scapulae were examined using the Spearman's rank correlation coefficient. A p-level of $<0.05$ was accepted as statistically significant. The distribution of measurements 


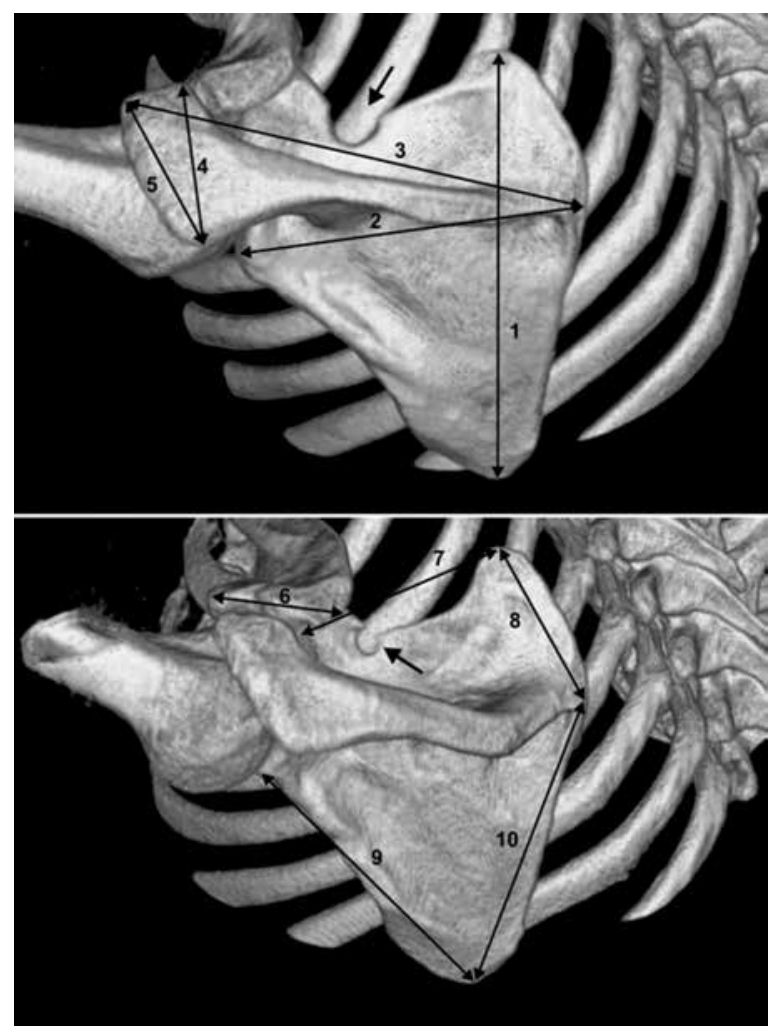

Figure 1. Three-dimensional volume rendering multidetector computed tomography. Anthropometric measurements of the scapula: 1 - morphological length; 2 - morphological width; 3 - projection length of scapular spine; 4 - maximal width of scapular spine; 5 - length of acromion; 6 - maximal length of the coracoid process; 7 - length of the superior border of the scapula; 8 morphological height of the supraspinous fossa; 9 - length of the lateral border of the scapula; 10 - morphological height of the infraspinous fossa; arrow — suprascapular notch.

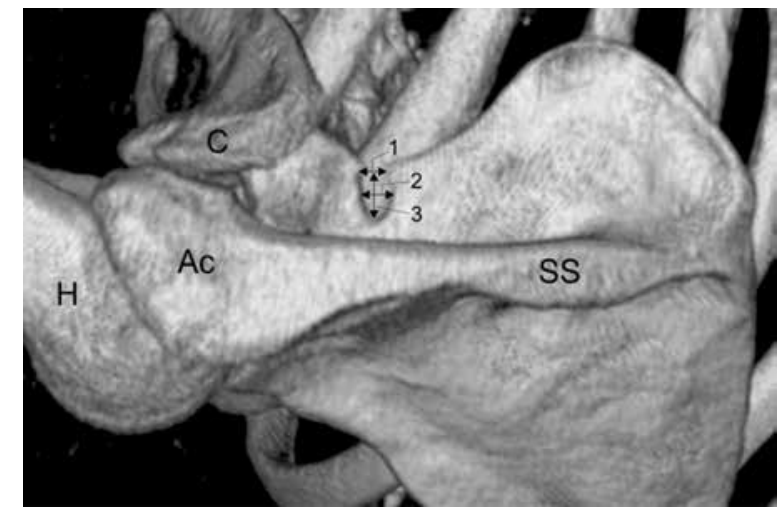

Figure 2. Three-dimensional volume rendering multidetector computed tomography of the scapula demonstrating measurements of the suprascapular notch: 1 - superior transverse diameter; 2 middle transverse diameter; 3 - maximal depth; Ac — acromion; $\mathrm{C}$ - clavicle; $\mathrm{H}$ - humerus; $\mathrm{SS}$ - scapular spine.

are presented as mean, standard deviation, median, minimum and maximum (Table 1).

\section{RESULTS}

Taking into consideration the correlation between the basic anthropometric measurements of the scapulae (Fig. 1) and the SSN dimension (Fig. 2), several correlations were detected.

It was found that the MD of the SSN correlated with the morphological length of the scapula $(r=0.2116, p=0.0272)$, the length of the lateral border of the scapula $(r=0.3038, p=0.0013)$ and the morphological width of the scapula $(r=0.3737$, $p=0.0001$ ) (Fig. 3). The STD of the SSN correlated

Table 1. Measurements of the scapulae

\begin{tabular}{|c|c|c|c|c|c|c|}
\hline \multirow[t]{2}{*}{ Scapula measurements [mm] } & \multicolumn{3}{|c|}{$\begin{array}{c}\text { Scapula with a longer maximal } \\
\text { depth (MD > STD) }\end{array}$} & \multicolumn{3}{|c|}{$\begin{array}{l}\text { Scapula with a longer superior } \\
\text { transverse diameter (STD > MD) }\end{array}$} \\
\hline & Mean \pm SD & Median & Min; Max & Mean \pm SD & Median & Min; Max \\
\hline Morphological length & $157.1 \pm 14.5$ & 160.4 & $124 ; 179.1$ & $150.2 \pm 11.91$ & 148.45 & $129 ; 177.1$ \\
\hline Morphological width & $109.68 \pm 5.56$ & 110.4 & $98.1 ; 118.6$ & $103.3 \pm 7.15$ & 103.35 & $87.7 ; 122.5$ \\
\hline Projection length of the scapular spine & $141.5 \pm 10.54$ & 140.9 & $114.2 ; 156.7$ & $136.0 \pm 10.1$ & 134.7 & $116.7 ; 163.5$ \\
\hline Maximal width of the scapular spine & $38.23 \pm 5.95$ & 36.2 & $29.3 ; 49.7$ & $36.49 \pm 5.9$ & 36.45 & $25.4 ; 51$ \\
\hline Length of the acromion & $43.45 \pm 6.56$ & 43.7 & $30.5 ; 60.5$ & $41.47 \pm 6.71$ & 40.5 & $24.2 ; 58.9$ \\
\hline Maximal length of the coracoid process & $44.2 \pm 4$ & 44.05 & $36.1 ; 52.2$ & $42.06 \pm 3.9$ & 41.85 & $31.4 ; 49.8$ \\
\hline Length of the superior border of the scapula & $77.98 \pm 10.44$ & 80.7 & $48.6 ; 95.2$ & $78.18 \pm 7.41$ & 77.7 & $62.9 ; 99$ \\
\hline Morphological height of the supraspinous fossa & $55.72 \pm 6.72$ & 56.2 & $42.8 ; 67.6$ & $52.74 \pm 9.58$ & 51.25 & $38.7 ; 112.2$ \\
\hline Length of the lateral border of the scapula & $137.9 \pm 8.46$ & 139.1 & $120.1 ; 153$ & $130.4 \pm 10.98$ & 129.15 & $112.6 ; 165.2$ \\
\hline Morphological height of infraspinous fossa & $117.4 \pm 12.22$ & 118.7 & $88.1 ; 141.6$ & $111.05 \pm 11.42$ & 110.3 & $56.6 ; 139.3$ \\
\hline
\end{tabular}

SD — standard deviation; Min — minimum; Max - maximum; MD — maximal depth of the suprascapular notch; STD — superior transverse diameter of the suprascapular notch 


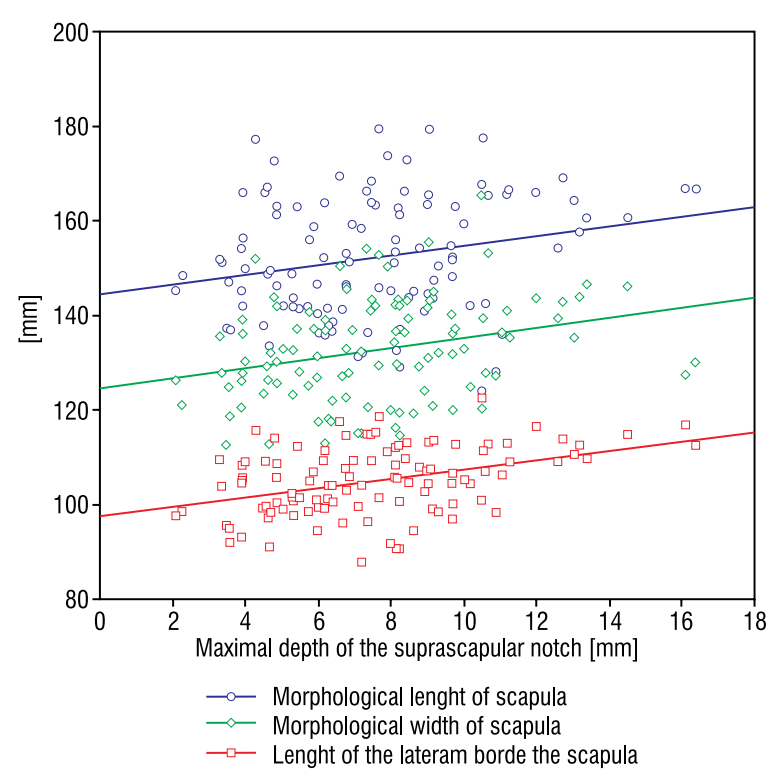

Figure 3. Graph comparing the relationship between the maximum depth of the suprascapular notch and the morphological length of the scapula, the morphological width of the scapula and the length of the lateral border of the scapula.

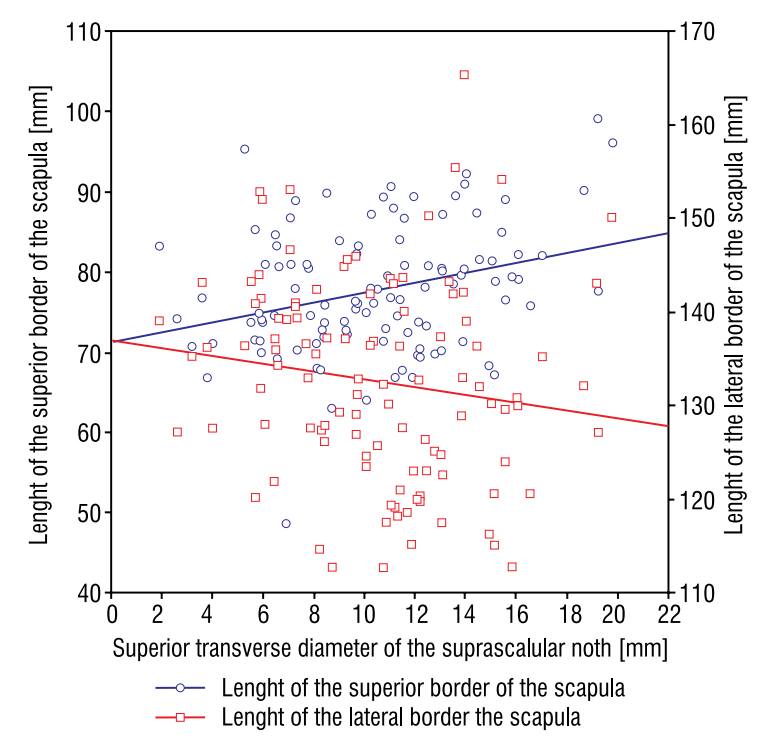

Figure 4. Graph comparing the correlation between the superior transverse diameter of the suprascapular notch and the length of the superior border of the scapula and the correlation between the superior transverse diameter of the suprascapular notch and the length of the lateral border of the scapula.

with the length of the superior border of the scapula $(r=0.2514, p=0.0084)$ and negatively with the length of the lateral border of the scapula $(r=-0.2075$; $p=0.0304$ ) (Fig. 4). In addition it was shown that the morphological length of the superior border of the scapula strongly correlated with the STD of SSN $(r=0.2514$,

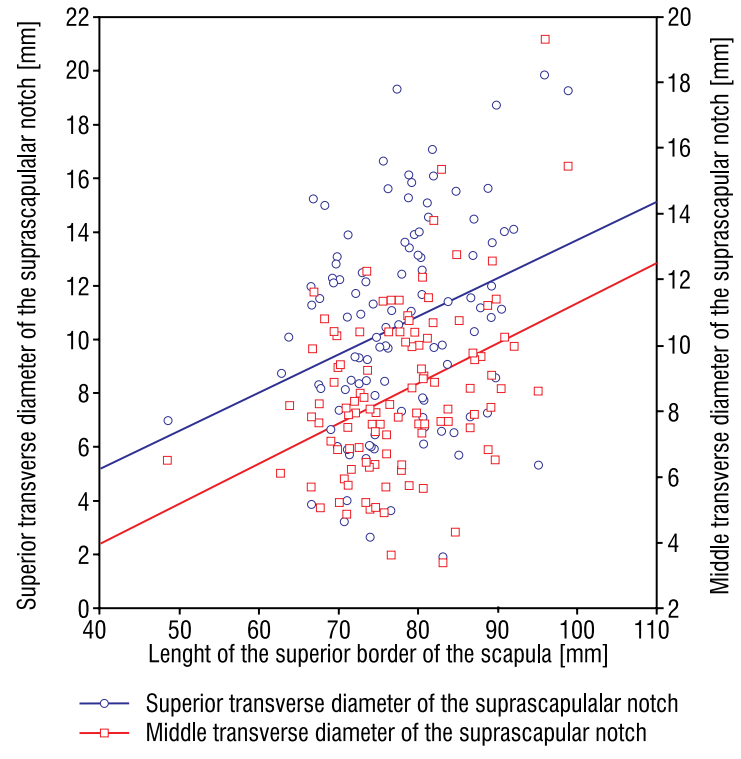

Figure 5. Graph comparing the correlation between the length of the superior border of the scapula and the superior transverse diameter of the suprascapular notch and the correlation between the length of the superior border of the scapula and the middle transverse diameter of suprascapular notch.

$p=0.0084)$ as well as with the MTD of the SSN but that correlation was lower $(r=0.0314, p=0.0008)$ (Fig. 5). Besides this, no statistically significant correlation exists between the dimensions of the SSN and the anthropometric dimensions of scapula.

\section{DISCUSSION}

The present study found a positive correlation between the depth of the SSN and the morphological length and morphological width of the scapula. This is supported by an anatomical study by Sangam and Devi [19], who observed a low positive correlation between MD of the SSN and morphological length of the scapula $(r=0.36, p<0.001)$, and between STD of the SSN and the morphological width of the scapula $(r=0.39$, $p<0.001)$ in an investigation of 104 dried scapulae. A similar study was carried out by Polguj et al. [12], who analysed a sample of 86 dried scapulae and demonstrated the existence of a direct correlation $(r=0.2651$, $p=0.0265$ ) between morphological length of the scapula and MD of the SSN, but no correlation between the morphological width of the scapula and the STD of the SSN [12].

According to our study, no positive correlation exists between STD or MTD of the notch and morphological width of the scapula. However, the STD of the SSN correlates with the length of the superior border 
of the scapula. So it may be concluded that scapulae with a wider superior border have a wider SSN. This is of note because it indicates that the STD of the SSN depends on the length of the superior border of the scapula but not on the morphological width of the scapula. As there is a positive correlation between the MD of the SSN and the morphological length of the scapula, it may be said that long scapulae may have deeper SSNs.

Such observation is important from clinical point of view in the aetiopathogenesis of SN neuropathy. Albino et al. [1] demonstrated that SN entrapment syndrome was more likely to be associated with a type III notch (with higher MD) because of its specific features [1]. A similar observation was previously made by Rengachary et al. [17].

According to Natsis et al. [10] and Dunkelgrun et al. [4], the size and shape of the SSN are the most important factors in the aetiopathology of SN entrapment formation. Rengachary et al. [17] note that a narrow SSN may predispose a patient to suprascapular neuropathy formation. Also, Antoniadis et al. [2] state that a V-shaped notch is more likely to be connected with this pathology. The influence of the shape of SSN is also supported by the sling effect, the first theory explaining SN entrapment proposed in 1979 by Rangrery et al. [17]. It posits that during motions of the upper limb, the $\mathrm{SN}$ can be pressed against the sharp bony margin of the SSN. Repeated kinking irritates the nerve and may induce microtraumas that result in injury [17]. When the SN travels through a "deep and narrow" SSN, it may be predispose to be injured by the sharp bony walls [1]. According to a radiological study by Polguj et al. [14], the maximal notch depth was significantly higher in males than in females $(p=0.00326)$. They also reported that the frequency of type I SSNs ("deep and narrow") was found to be higher in males (28.45\%) than in females (18.66\%) [14]: an important observation because it explains why males are approximately three to 4 times more likely to suffer from a suprascapular neuropathy than females [21]. It may also confirm the sling effect proposed by Rangrery et al. [17].

The present study aims to establish a correlation between the dimensions of the SSN and the basic anthropometric measurements of the scapula. Such knowledge is clinically valuable, because it enables the depth of the SSN to be anticipated by measuring the morphological height and width of the scapula in living people without the need to use methods based on radiation like $\mathrm{X}$-ray films.

\section{CONCLUSIONS}

The study presents a correlation between the morphological length of the scapula and the MD of the SSN. It could be suggest that individuals with longer scapulae have deeper notches. No correlation was found between the morphological width of the scapula and the STD of the SSN. However, the STD of the SSN correlates with the length of the superior border of the scapula. It may be concluded that scapulae with a wider superior border have a shallower SSN.

\section{ACKNOWLEDGEMENTS}

The paper was supported by grant No. 503/ /2-031-01/503-01 from the Medical University of Lodz, Poland.

\section{REFERENCES}

1. Albino P, Carbone S, Candela V, Arceri V, Vestri AR, Gumina S (2013) Morphometry of the suprascapular notch: correlation with scapular dimensions and clinical relevance. BMC Musculoskelet Disord, 24; 14: 172.

2. Antoniadis G, Richter HP, Rath S, Braun V, Moese G (1996) Suprascapular nerve entrapment: experience with 28 cases. J Neurosurg, 85: 1020-1025.

3. Dietrich LN, Bentley A, Savage JA, Momaya AM, Larrison MC, McGwin G, Ponce BA (2015) Arthroscopic decompression at the suprascapular notch: a radiographic and anatomic roadmap. J Shoulder Elbow Surg, 24: 433-438.

4. Dunkelgrun M, lesaka K, Park SS, Kummer FJ, Zuckkerman JD (2003) Interobserver reliability and intraobserver reproducibility in suprascapular notch typing. Bull Hosp Joint Dis, 61: 118-122.

5. Duparc F, Coquerel D, Ozeel J, Noyon M, Gerometta A, Michot C (2010) Anatomical basis of the SNentrapment, and clinical relevance of the supraspinatus fascia. Surg Radiol Anat, 32: 277-284.

6. Gerard-Białko D (1984) Variability of positioning and shape of the shoulder blade in man. Przegląd Antropol, 50: 113-119.

7. Gumina $S$, Albino $P$, Giaracuni $M$, Vestri AR, Ripani $M$, Postacchini $F$ (2011) The safe zone for avoiding suprascapular nerve injury during shoulder arthroscopy: an anatomical study on 500 dry scapulae. J Shoulder Elbow Surg, 20: 1317-1322.

8. Huri G, Uzümcügil A, Biçer OS, Ozturk H, McFarland EG, Doral MN (2015) An alternative endoscopic portal for suprascapular nerve approach: an anatomic study. Knee Surg Sports Traumatol Arthrosc, 23: 1511-1517. doi: 10.1007/s00167-014-2903-y.

9. Malinowski A, Bożiłow W (1997) Podstawy antropometrii (metody, techniki, normy). PWN, tódź.

10. Natsis K, Totlis T, Tsikaras $P$, Appell HJ, Skandalakis $P$, Koebke J (2007) Proposal for classification of the suprascapular notch: a study on 423 dried scapulas. Clin Anat, 20: 135-139.

11. Olivier G (1960) Pratique anthropologique. Le scapulum. Vigot Freres, Paris, pp. 194-201. 
12. Polguj M, Jędrzejewski KS, Podgórski M, Topol M (2011) Correlation between morphometry of the suprascapular notch and anthropometric measurements of the scapula. Folia Morphol, 70: 109-115.

13. Polguj M, Jędrzejewski K, Majos A, Topol M (2012) The trifid superior transverse scapular ligament: a case report and review of the literature. Folia Morphol, 71: 118-120.

14. Polguj M, Sibiński M, Grzegorzewski A, Grzelak P, Majos A, Topol M (2013) Variation in morphology of suprascapular notch as a factor of suprascapular nerve entrapment. Int Orthop, 7: 2185-2192.

15. Polguj M, Jędrzejewski K, Topol M (2013) Variable morphology of the anterior coracoscapular ligament: a proposal of classification. Ann Anat, 195: 77-81.

16. Rengachary SS, Burr D, Lucas S, Hassanein KM, Mohn MP, Matzke H (1979) Suprascapular entrapment neuropathy: a clinical, anatomical, and comparative study. Part 1: Clinical study. Neurosurgery, 5: 441-446.
17. Rengachary SS, Burr D, Lucas S, Hassanein KM, Mohn MP, Matzke H (1979) Suprascapular entrapment neuropathy: a clinical, anatomical, and comparative study. Part 2: anatomical study. Neurosurgery 5: 447-451.

18. Rothe C, Steen-Hansen C, Lund J, Jenstrup MT, Lange KH (2014) Ultrasound-guided block of the suprascapular nerve: a volunteer study of a new proximal approach. Acta Anaesthesiol Scand, 58: 1228-1232.

19. Sangam MR, Sri Sarada Devi S (2014) Morphometry of suprascapular notch and its correlation with that of scapula. J Clin Diagn Res, 8: AM01-2.

20. Toneva D, Nikolova S (2014) Morphology of suprascapular notch in medieval skeletons from Bulgaria. Folia Morphol, 73: 210-215.

21. Zehetgruber H, Noske H, Lang T, Wurnig C (2002) Suprascapular nerve entrapment. A meta-analysis. Int Orthop, 26: 339-343. 